\title{
A NEW PHEIDOLE WITH REVERSED PHRAGMOSIS (HYMENOPTERA: FORMICIDAE)*
}

\author{
By William L. Brown, JR. \\ Department of Entomology, Cornell University \\ INTRODUCTION
}

A number of ants have plug-shaped heads, known or assumed to be used to stopper the nest entrance. This phenomenon, called phragmosis, is best understood in certain groups of Camponotus and Cephalotini (e.g. Wheeler I910: 209-212, Szabó-Patay I928, Creighton and Gregg 1954), but Wheeler (I901 : 534; 1927) also described species with phragmotic-like heads in Pheidole, Crematogaster and the dacetine genus Colobostruma, while Patrizi ( 1948 ) published the problematical Solenopsis (Crateropsis) elmenteitae (placed by Ettershank, 1966, in Oligomyrmex). In most of these forms, either the queens or the soldiers, or both, are the phragmotic castes; in Colobostruma leae, the assumed phragmotics are the queen and the monomorphic workers.

In the new species of Pheidole described below, phragmotic behavior at some stage of the life cycle is indicated only for the queen caste, and even then is inferred from her aberrant body form. But in this case, the plug is formed, not by the head, but by the highly modified gaster (Figs. 6 and 7 ).

Two queens showing this plug-like modification of the gaster were taken separately from rotten wood in rain forest in the general vicinity of Manaus during my collecting trip of 1962 in the Brazilian Amazon. In one case, and possibly in both, the queens belonged to definite colonies with workers, soldiers and brood. (Notes on collection M-6o are ambiguous because two Pheidole queens, one of embolopyx and one of a totally different species, were in the vial with this number, but the notes state that "the" queen was taken apart from the soldiers, workers and brood. Probably one of the two queens was taken up in the aspirator along with bits of rotten wood without my knowing it.)

The queen's thickened scape base (with a gelatinous sheath) and the largely smooth and shining alitrunk with overhanging scutal margins, are "protective" characters suggesting social parasitism as a way of nest-founding for this caste. The strong similarities in color, sculpture and pilosity between the queens and the accompanying

*Manuscript received by the editor November 27, 1967 
soldiers weigh against considering them as different species, so perhaps the queens of the new species found nests by entering the nest of some other Pheidole species. If so, then what is the need for the phragmotic posterior in the queen? Does she enter a circular burrow in a twig or in rotten wood in or near the host nest, and seal herself off from the host workers by phragmosis?

Whatever the truth proves to be, it will certainly make a fascinating story when the life history of the new Pheidole is better known. One interesting but inconspicuous feature is the presence of a few short, fine, outstanding setae ranged around the rim of the phragmotic face of the gaster (Fig. 6); undoubtedly these serve as "vibrissae", or sense hairs that inform the insect as to how snugly the plug is fitting into whatever passage or entrance it presumably blocks during some critical phase of adult life.

\section{Pheidole embolopyx sp. nov. (Figs. I-7)}

Holotype soldier: TL (total outstretched length, including mandibles) 3.5, HL (length of head without mandibles) I.o3, HW (without eyes) 0.96, (Cephalic Index 93), WL (diagonal length of alitrunk in side view, without pronotal cervix) 0.9I, scape L (chord to basal collar) 0.75 , greatest diameter of compound eye $0.16 \mathrm{~mm}$.

Form of head and body as in Figs. I and 3. Median sulcus of head reaching to frontal triangle; triangle and middle of clypeus smooth and shining, as are mandibles except for basolateral striation. As seen in perfect full-face view when held straight back, the scapes miss the apices of the occipital lobes by somewhat more than the width of the scape apex. The scapes appear more slender in some front views than they do in Fig. 3, and more curved towards the base (compare Fig. I ).

The alitrunk resembles those of $P$. triconstricta and $P$. radoszkow$s k i i$, with its deeply notched mesonotum and lesser constriction of the posterior pronotum along its suture with the mesonotum (indicated by black shading in Fig. I). In dorsal view, raised but rounded humeri project from the middle of the pronotal sides. Propodeal dorsum sulcate its length, the sulcus wider behind.

Petiole slender, with a rather long anterior peduncle and anteroposteriorly compressed, almost squamiform node ( $W$ about $0.14 \mathrm{~mm}$ ), with horizontal crest, vertical sides, and rounded corners as seen from behind. Postpetiole bun-shaped as seen from above, only about I/3 wider than the petiole ( $W 0.20 \mathrm{~mm}$ ) and its own length (0.I4 $\mathrm{mm}$ ) ; sides gently rounded in front, then nearly straight to posterior 


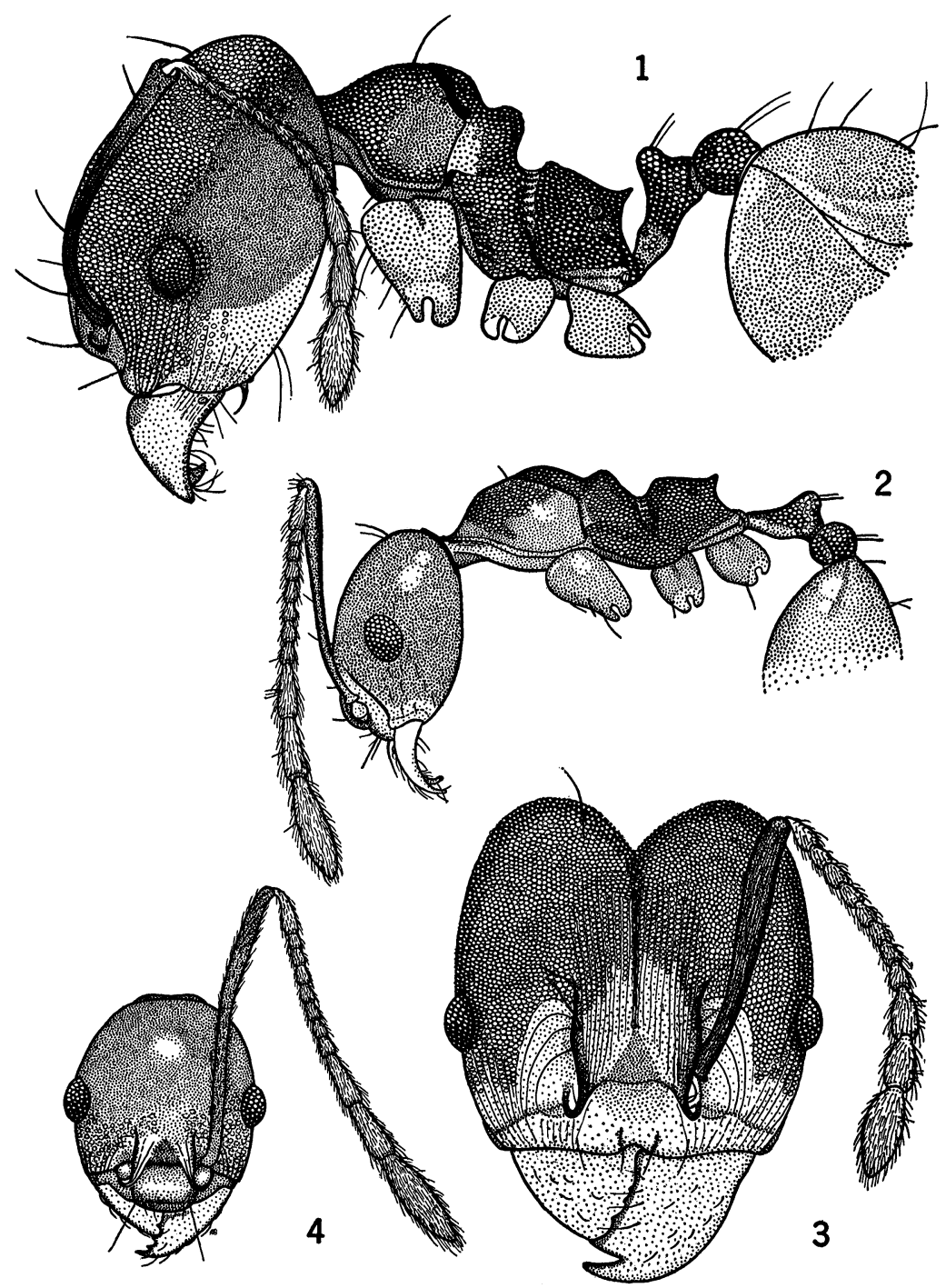

Figures 1-4, Pheidole embolopyx sp. nov., side views of body and full-face views of head. Figures 1 and 3, holotype soldier; figures 2 and 4, worker minor from type nest series (M-77). Drawings by Margaret Menadue and the author, all to same scale. 
border, which is very feebly constricted; no trace of lateral conules. Gaster (slightly dented) about $0.64 \mathrm{~mm}$ wide near the middle, with the usual subtruncate anterior end; strongly convex both above and below. Legs rather long and slender (longer than in radoszkowskii), but with moderately incrassate femora and tibiae.

Dorsum of head (face) densely reticulopunctulate and opaque, except for the shining areas noted above; area between frontal carinae and cheeks in front of eyes finely longitudinally costulate (Figs. I and 3 ). Sides of head behind (below) eyes, and all of ventral surface of head, smooth and shining. Alitrunk, both waist segments and basal 3/5 of first gastric tergite reticulopunctulate and opaque. Most of legs, a large spot on each side wall of pronotum, and most of gaster smooth and shining. Antennal scapes finely punctulate, weakly shining, with some indistinct longitudinal costulae mainly near base.

Longer erect setae, mostly bilaterally paired, arranged as shown in the figures (see especially Fig. I). Head, mandibles, legs and gastric dorsum, especially the smooth surfaces, with sparse, fine, short appressed hairs. Scapes, femora, tibiae, coxae and trochanters each with I-3 short, fine oblique standing hairs.

Color distinctive: body castaneous, including scapes, frontal triangle and posteromedian lobe of clypeus, margins of mandibles and frontal carinae, and the upper $3 / 4$ of the sides of the head, including compound eyes (pattern shown in Figs. I and 3, especially the former); alitrunk and scapes darker than the rest, almost piceous. Legs and scapes dull brownish yellow. Dorsal surface and lower sides of head a contrasting light yellow, along with anterior clypeus and most of mandibles. This color pattern resembles at a glance that of Pheidole punctatissima, the common epiphyte dweller of Middle America.

Soldier variation: Of the paratypes, 4 soldiers were measured; a small specimen from sample M-77 has HL I.0O, HW $0.94 \mathrm{~mm}$ (CI 94), while the largest soldier in M-6o measures: TL 3.3, HL 0.08, HW r.or (CI 94), WL 0.91. The other soldiers are intermediate in size (HL), but one from the Igarapé Marianil berlesate has HL 1.07 by HW $1.02 \mathrm{~mm}$ (CI 95). Soldiers in the paratype series vary in depth of coloration, but the general pattern is the same. Some examples have an extra pair of erect hairs on the mesonotum.

Worker (from type nest series): TL 2.3, HL o.58, HW 0.46 (CI 79), WL 0.75, scape L 0.73, greatest diam. eye $0.12 \mathrm{~mm}$.

Form, sculpture and pilosity well portrayed in Figs. 2 and 4. Note the shape of the back of the head, rather narrowly rounded as seen 

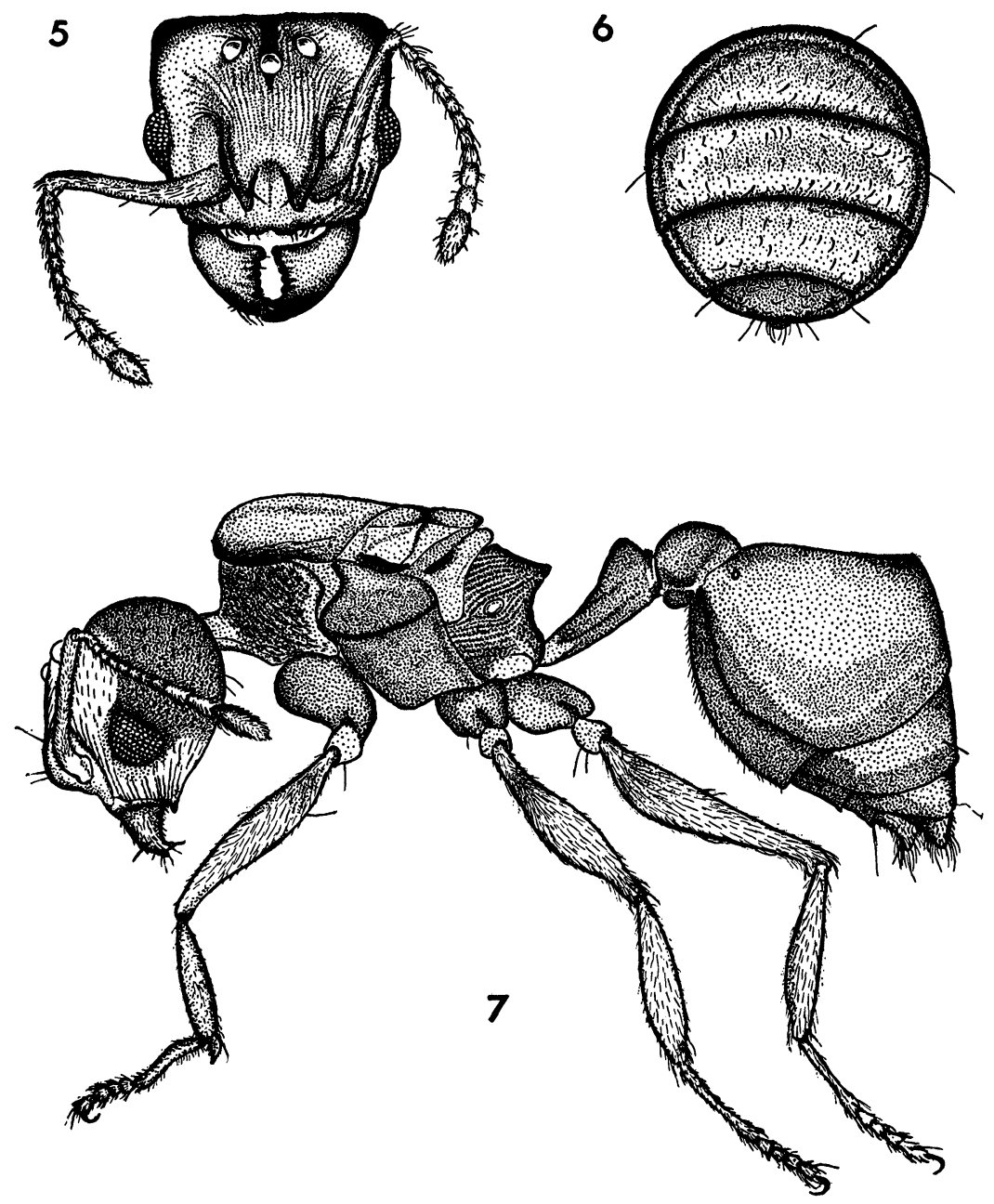

Figures 5-7, Pheidole embolopyx sp. nov., queen, composite drawings from two specimens, one from collection M-77 (type nest) and one from M-60. Figure 5, head in full-face view. Figure 6, gaster viewed from behind to show face of "plug." Figure 7, side view of the whole insect. Drawings by Margaret Menadue, Frances McKittrick and the author, all drawn to the same scale, which is different from that of Figures 1-4. 
in full-face view, with a narrow but distinct occipital collar. Except for the head, the sculpture is as in the soldier, but the reticulation of the postpetiolar disc and the anterior half of the gaster is more superficial, and the integument here somewhat shining. Head smooth, mostly shining, with sparse fine short appressed hairs in addition to the longer standing setae; anterior cheeks, especially the parts just mesad of the eyes, finely reticulopunctulate and subopaque, with fine costulae disposed as shown in Fig. 4. Mandibles smooth and shining, with sparse fine punctures. Outstanding pilosity positioned as in soldier.

Color light castaneous; mandibles, antennal funiculi and legs brownish yellow.

Worker variation: Of 6 paratype workers measured, only one differed from the specimen described above by much more than the average measurement error of about $\pm 0.0 \mathrm{~mm}$; this is a worker from the Igarapé Marianil berlesate that is a little larger, darker and more heavily sculptured than others in the sample available: TL 2.4, HL 0.60, HW 0.49 (CI 8r), WL $0.75 \mathrm{~mm}$. It has the vertex largely microreticulate and subopaque instead of shining, and its color is prevailingly darker brown than the other workers. Otherwise, the workers show noticeable but not extreme variation in depth of coloration, and some have an extra pair of erect hairs on the mesonotum.

Female (dealate, from type nest series): TL 5.7, HL I.00, HW I.12 (CI I12), WL I.65, scape L o.80, greatest diam. compound eye $0.3 \mathrm{I}$, of median ocellus $0.1 \mathrm{I} \mathrm{mm}$.

Form shown in Figs. 5, 6 and 7. Head wide, with straight posterior margin in full-face view. Antennal scapes reaching posterior margin of head when held straight back, incrassate and strongly curved at base, the incrassate portion further thickened by a jacket of whitish gelatinous material that collapses in dried specimens (Fig. $5)$; this was much better developed in one specimen than in the other, and could possibly represent foreign material in part. Frontal lobes thick, a well-marked median sulcus extends from posterior border of head to a point in front of median ocellus. Clypeus with a feeble median carina in its posterior half.

Alitrunk robust, mesonotum broad and depressed, sides of scutum produced as thick curved shelves decidedly overhanging pronotum. Petiole with a broad ( $W 0.22 \mathrm{~mm}$ ) transverse node, its rounded border emarginate in the middle as seen from behind; its peduncle strongly depressed and broadened ( $\mathrm{W}$ 0.15 $\mathrm{mm}$ ), with very convex margins as seen from above. Petiole subelliptical, about $0.56 \mathrm{~mm}$ 
wide, the sides produced as narrowly rounded angles, but not strictly speaking as conules.

Gaster of the highly modified form shown in Figs. 6 and 7. The truncate portion involves large parts of the first 4 tergites, which in the living, unswollen gaster fit together to produce a nearly flat circular disc surrounded by a heavy raised ridge that is continuous except for a small sector at the edge of the fourth segment. This disc is weakly shining, finely reticulate and with numerous very small, spaced tubercles with smooth, rounded heads; and also with small, curved, appressed pennant-shaped hairs.

Dorsum of head finely reticulopunctulate, with overlying costulation (striation) as shown in Figs. 5 and 7. Frontal area, middle of clypeus, upper surfaces of mandibles, "occipital" surface and a large area above and behind the compound eyes, extending to the ventral surface of the head, smooth and shining. The smooth areas of the back and sides of the cranium coincide almost exactly with the dark brown pigment pattern as shown in Figs. 5 and 7. Antennal scapes finely punctulate, shining, on apical halves. Alitrunk and legs predominantly smooth and shining, except for these striate to punctatestriolate areas: sides of pronoum (steeply oblique), anterior surface and lateral margins of scutum (horizontal, paralleling margins), sides of propodeum (prevailingly longitudinal, as shown in Fig. 7).

Petiole and postpetiole finely and densely punctulate, opaque, except for upper anterior surface of petiole, which is almost smooth and definitely shining. Base of gaster punctulate-striate, with radiating costulae, passing behind into a smooth, shining dorsal surface (in front of the truncate portion) and finely reticulate, shining sides; ventral base of gaster sculptured like the tergal base, but passing into shining, smooth and reticulate areas caudad.

Paratype female (dealate) from collection M-6o, not measured, but nearly the same size as the queen of the type nest, described above. The scape bases of the paratype are thicker, and originally carried more of the whitish gelatinous substance.

Holotype soldier (Museum of Comparative Zoology, Harvard University, Cambridge, Massachusetts, USA) taken together with queen, other soldiers, workers and brood, from a small colony (M-77) nesting in rotten wood on the rain forest floor near the Igarapé Marianil, which is a small creek just beyond Kilometer 5 on the Rio Branco Road after its branching from Amazonas Ruta I ("Itacoatiara Highway"). The road fork is $19 \mathrm{~km} \mathrm{NE}$ of Manaus, and the igarapé is about $24 \mathrm{~km} \mathrm{NE}$ of Manaus by road. This forest is on 
undulating country with sandy soil. Although the forest was very dark and did not appear to be seriously disturbed, we found few really large trees, and there were many spiny palms in the undergrowth. Probably the area had been selectively logged (26 August, ig62, W. L. Brown, Jr. leg.).

Workers and soldiers (labeled "BF") were also taken in leaflitter berlesates from the vicinity of Igarapé Marianil during the same month, and the other paratypes (M-6o) came from partially newly cut hillside rain forest near kilometer 50 on the western side of Amazonas Ruta I (24 August 1962, Brown leg.). The M-60 ants were nesting in a small spongy piece of rotten branch (without bark) on the forest floor. The soil was sandy, with thin litter, and the country looked very much like that at Igarapé Marianil, about $30 \mathrm{~km}$ to the west. The phragmotic nature of neither queen was noticed until after they had been captured, and so no particular note was made of their behavior or position within the nests.

Paratypes are deposited with the holotype and in the collections of W. W. Kempf and Cornell University, Ithaca, New York.

Pheidole embolopyx appears to belong to the triconstricta group, but the color and sculpture of the soldier, as well as the narrowlyrounded occiput of the worker minor, will separate the new species from the several forms clustered around $P$. triconstricta and $P$. radoszkowskii. The types have been compared with all likely related species in the Museum of Comparative Zoology, the W. W. Kempf (ex-Borgmeier) Collection, and several of the principal European ant collections, and are thought to be distinct. The queen is of course unique in form among Pheidole known from this caste, but for most New World members of the genus, the queen remains undescribed. After all is said and done, $P$. embolopyx may eventually end in the synonymy of some named species $I$ have not taken into account. Certainly, the known described and undescribed New-World species of Pheidole number in the hundreds, and they remain unrevised. The biological interest of this particular species dictated that it should be described without further delay, regardless of the small risk that it might turn out to have received a name previously.

\section{ACKNOWLEDGEMENTS}

Thanks are due Dr. Djalma Batista and the Instituto Nacional de Pesquisas da Amazonia, for hospitality and transportation during the collecting period at Manaus in 1962 ; Dr. Frances McKittrick for aid with the drawings; Dr. Walter W. Kempf, OFM, for searching his 
collection for related Pheidole species; Dr. E. O. Wilson for critically reading the manuscript; and the United States National Science Foundation for its support of the project of which this is a part (mainly through grants, G-2368o and GB-5574X).

\section{References Cited}

Creighton, W. S. and R. E. Gregg.

1954. Studies on the habits and distribution of Cryptocerus texanus ... Psyche, 61: 41-57.

EtTERshan K, G.

1966. A generic revision of the world Myrmicinae related to Solenopsis and Pheidologeton (Hymenoptera: Formicidae). Aust. J. Zool., 14: 73-171 (cf. pp. 119 ff.).

Patrizi, S.

1948. Contribuzione alla conoscenza delle formiche e dei mirmecofili dell'Africa orientale. VI. Crateropsis elmenteitae, nuovo sottogenere aberrante di Solenopsis Westw. (Hymenoptera Formicidae). Boll. Ist. Entom. Univ. Bologna, 17: 174-176.

Szabo-Patay, J.

1928. A kapus-hangya (Well illustrated article on Camponotus truncatus). Természettudományi Közlöny, pp. 215-219.

WHEELER, W. M.

1901. The compound and mixed nests of American ants. Part II. The known cases of social symbiosis among American ants. Amer. Naturalist, 35: 513-539 (cf. pp. 534-535).

1910. Ants. New York, Columbia University Press.

1927. Tht physiognomy of insects. Quart. Rev. Biol., 2: 1-36 (cf. pp. 31-32). 

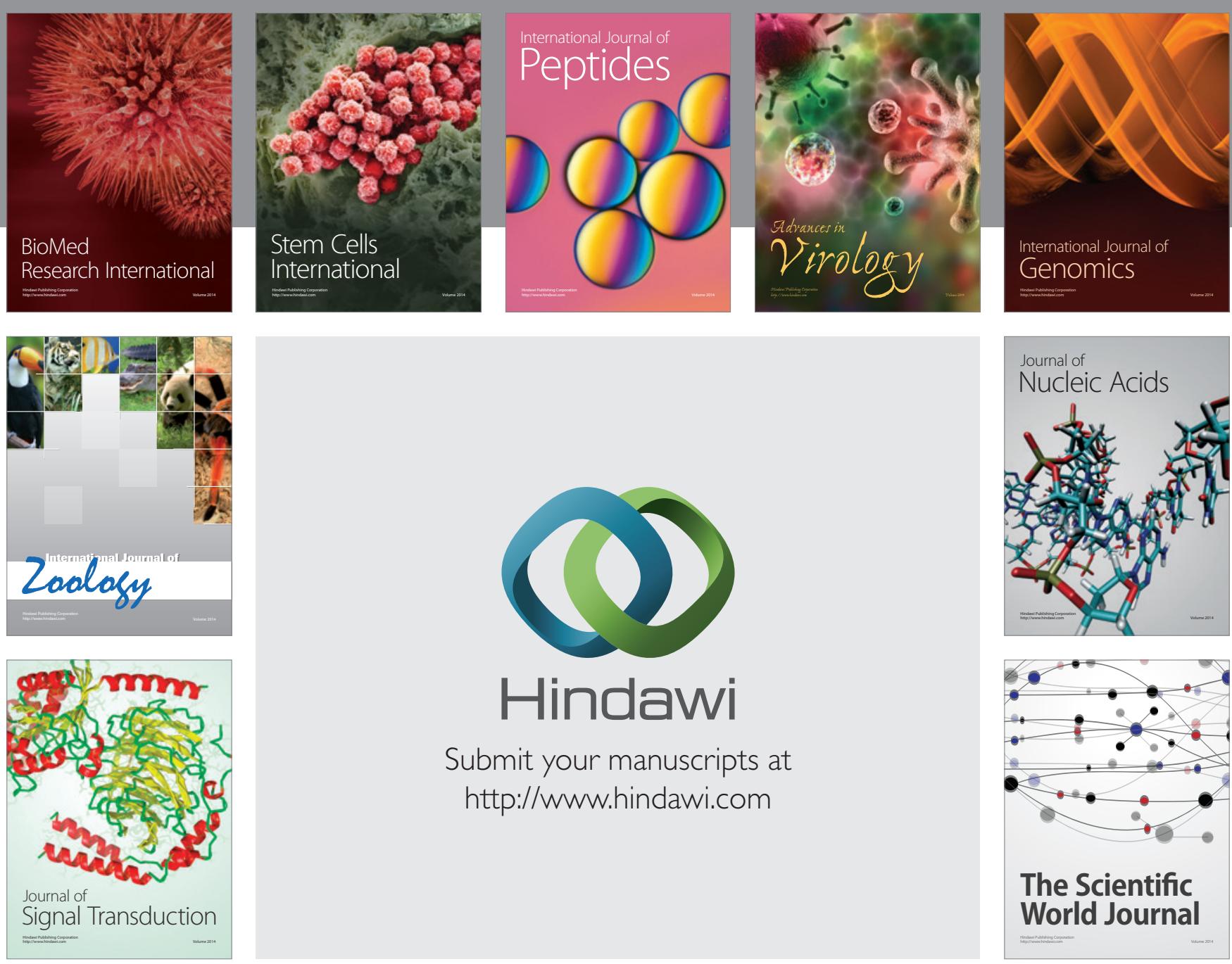

Submit your manuscripts at

http://www.hindawi.com
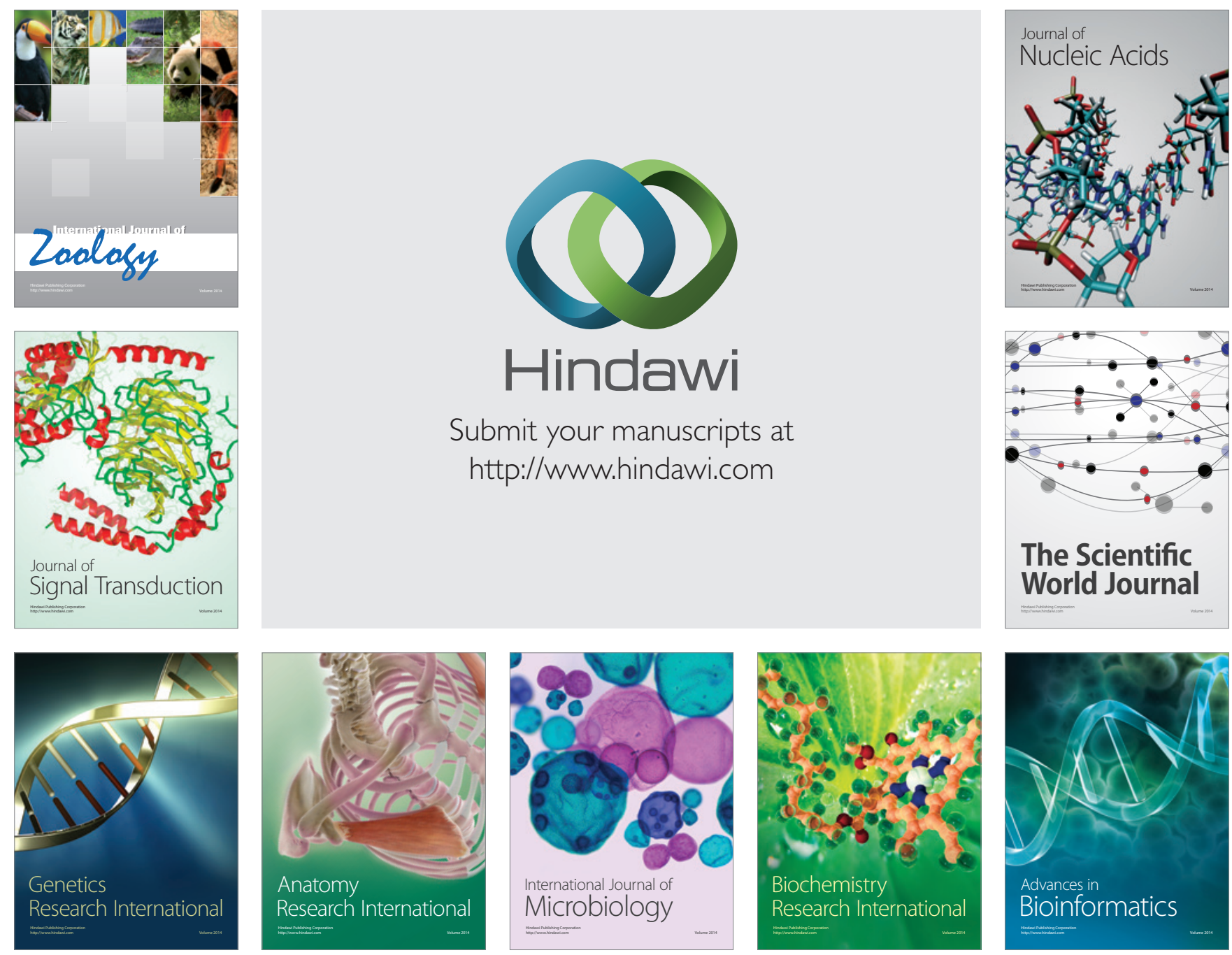

The Scientific World Journal
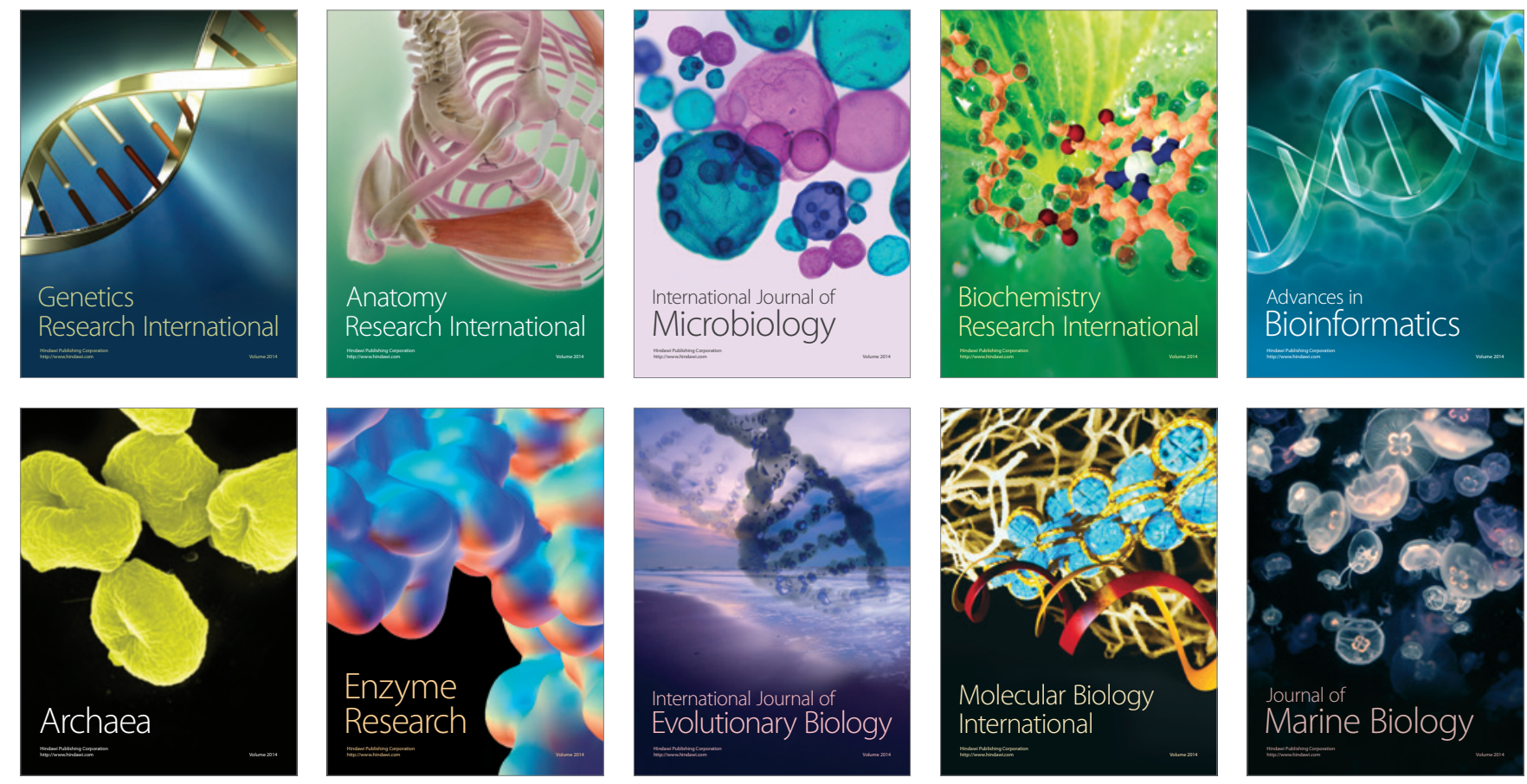